\title{
Screening a supplier with fairness preference
}

\author{
Kaiming Zheng ${ }^{1, \mathrm{a}}$, . Xiaoyuan Wang ${ }^{2, \mathrm{~b}}$, Debing $\mathrm{Ni}^{3, \mathrm{c}^{*}}$ \\ ${ }^{1}$ School of Management and Economics University of Electronic Science and Technology of China Chengdu, China \\ ${ }^{2}$ School of Management and Economics University of Electronic Science and Technology of China Chengdu, China \\ ${ }^{3}$ School of Management and Economics University of Electronic Science and Technology of China Chengdu, China
}

\begin{abstract}
This paper is to study how a firm to screen an external supplier who has fairness preference using a general screening framework. The supplier with fairness preference provides products or services to the firm, and the firm designs a contract to screen the preference type of suppliers. The supplier's fairness preference is adjusted by their ability difference, this paper analyzes how the supplier's ability difference affect the optimal contract variables under the standard framework. The results illustrate that the larger ability difference will narrow the output difference between two different type suppliers. Associated with fairness preference, the probability distribution can increase or decrease the output difference. Furthermore, different strengths of the fairness preference would amplify or shrink the output difference between two different type suppliers.
\end{abstract}

\section{INTRODUCTION}

A superior external supplier can help a company to improve product quality and customer satisfaction, reducing service waiting time, the price of products or services, and enhancing the company's core competitiveness effectively 1 . The companies can also obtain information about related production processes from external suppliers to evaluate the efficiency of the company's organizational structure, affecting the organizational structure of the company 2,3 . The selection of a suitable supplier has become a very important operational decision issue 4 .

Supplier selection usually goes through the process of determining the criteria of supplier evaluation, selecting which suppliers to enter the evaluation according to the criteria, conducting the evaluation, and finally selecting the most suitable supplier 5. However, there exists information asymmetry between enterprises and potential suppliers: potential suppliers have a better understanding of their production costs, equipment capacity, worker's productivity, team cooperation, financial situation, and so on. Before the evaluation, the enterprise may use public information or request relevant data from potential suppliers for evaluation, but these potential suppliers may not provide credible data to the public or the firm who is searching for a supplier. If becoming a supplier is profitable, those potential suppliers may have incentives to pretend to be a supplier that suits the needs of the firm. In this sense, the supplier selection problem can be considered as a screening or adverse selection problem.

In the classical screening problem, the agent has private information. Akerlof's analysis of the lemon market 6 shows that such information asymmetry leads to low efficiency and even the disappearance of the market. To achieve the efficient allocation of resources, the principal needs to design a contract to reveal the private information of the agent. At the same time, for the purpose of revelation, the principal needs to pay certain information rent to the agent. The principal is faced with the tradeoff between the rent extraction and efficiency 7,8 .

The key assumption in the classical theory is that all participants in the contract care only about their own pecuniary outcome. However, a large number of studies 9-1011 have shown that decision-makers care not only about their own interests, they also take a fair view of distribution results. Typically, behavioral economicsts define fairness as inequality aversion based on the distributional outcome 10,11. The results of a higher distribution result than others' circumstances or below others can lead to negative utility, which is called the Advantageous inequality aversion and the Disadvantageous inequality aversion respectively. Another related stream of literature is about social comparison. The early formal study shows that social comparison and fairness concern have impact on labor relations originated from 1920 12. An individual will compare his wage to another, if he feels that he has been treated unfairly, his productivity and cooperation may be negatively affected. For example, both 13 and 14 shown that workers will reduce their effort provision if they perceive unfair wages. In the supply chain relationship, an unfairness outcome may lead to the coordination failure and efficiency loss of the supply chain $15,16.17$ show that when the agent has social preference, the principal should consider these factors in the contract design. They also demonstrate the feasibility and necessity of

\footnotetext{
akm@std.uestc.edu.cn

bwangxy@uestc.edu.cn

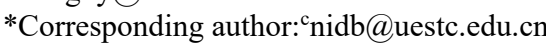


incorporating social preference into the contract design through field experiment study 18 .

There is abundant literature focus on fairness concern or social comparison, but little paper takes agents' ability differences into their consideration. Actually, the practitioners have already considered the link between the payment scheme and ability difference. For example, Skill-Based Pay is a widely used pay scheme in many big companies. This scheme is a system to reward their employees with a monetary value on their skills, regardless of their jobs or tasks. This system reduces the firm's costs of hiring and brings flexibility and productivity to the firm 19-20. In this paper, we build a model to capture how a firm screen the external suppliers who have fairness preference. In our model, the external supplier considers not only differences in their revenues but also differences in their products and services cost. Our result shows that our adjusted fairness preference would increase output difference between two types suppliers, and the fairness concern can amplify or diminish the effect.

\section{MODEL AND EQUILIBRIUM}

\subsection{Background}

We consider a firm needs an external supplier to provide him $q$ unit product or service, and the firm would obtain value $S(q)$ from these products or services. We define $S^{\prime}>0, S^{\prime \prime}<0$ and $S(0)=0$, that is the marginal value of products or services is positive and strictly decreasing in the number of products purchased by the firm. The external supplier has a positive marginal $\cos t \theta_{H}$ or $\theta_{L}$. The marginal cost information is the external provider's private information. The supplier would receive a transfer $w_{i}(i=H, L)$ from the firm and she provides the products/services quantity $q_{i}(i=H, L)$. Figure 1 shows the timing of the model: the supplier knows her own cost type; then the firm designs a take-it-or-leave-it contract; the supplier can accept or reject the contract; the supplier honors the contract upon her acceptance. Note that the information asymmetry about the marginal cost has already existed before the contract design.

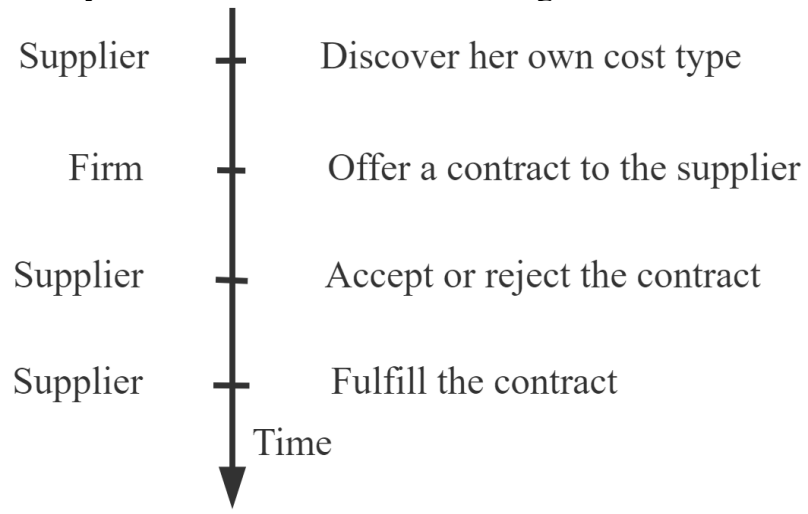

Figure 1. The timing of the model

\subsection{Social comparison and fairness preferences}

Once the supplier knows her own ability type, he will compare her ability to the others. The traditional fairwage hypothesis only supposes that the agents compare their own payoff to others, ignoring their ability differences. In this paper, we propose that the agents not only compare their transfer but their ability difference as well. We define $\Delta w=w_{i}-w_{j}$, and model the supplier's utility function using a reference-dependent way:

$U_{i}=w_{i}-\theta_{i} q_{i}+\lambda \frac{\Delta w}{\Delta \theta}$

The utility function captures the idea that the supplier receives additional (dis)utility from inequality of transfers and the effect of inequality is associated with their ability differences.

\subsection{Screening model}

We assume that both the firm and the supplier are riskneutral. The firm only knowns that the supplier has a higher $\operatorname{cost} \theta_{H}$ with probability $p$ and lower $\operatorname{cost} \theta_{L}$ with probability $1-p$, and $\Delta \theta=\theta_{H}-\theta_{L}>0$. The firm receives value from the supplier's products or services is $S(q)$, where $S(0)=0, S^{\prime}(q)>0$ and $S^{\prime \prime}(q)<0$. The firm has to pay $w_{H}$ and $w_{L}$ for the supplier's production $q_{H}$ and $q_{L}$, thus the firm's expected utility function is:

$V=p\left[S\left(q_{H}\right)-w_{H}\right]+(1-p)\left[S\left(q_{L}\right)-w_{L}\right](2)$

To screen the supplier, the principal has to design a contract $\left\{\left(w_{H}, q_{H}\right) ;\left(w_{L}, q_{L}\right)\right\}$ which satisfies the following constraints:

$$
\begin{gathered}
U\left(\theta_{H}, w_{H}, q_{H}\right)=w_{H}-\theta_{H} q_{H}+\lambda \frac{w_{H}-w_{L}}{\Delta \theta} \geq 0 \quad(\text { IRH }) \\
U\left(\theta_{L}, w_{L}, q_{L}\right)=w_{L}-\theta_{L} q_{L}+\lambda \frac{w_{L}-w_{H}}{\Delta \theta} \geq 0 \quad(\text { IRL }) \\
U\left(\theta_{H}, w_{H}, q_{H}\right) \geq w_{L}-\theta_{H} q_{L}+\lambda \frac{w_{L}-w_{H}}{\Delta \theta} \quad(I C H) \\
U\left(\theta_{L}, w_{L}, q_{L}\right) \geq w_{H}-\theta_{L} q_{H}+\lambda \frac{w_{H}-w_{L}}{\Delta \theta} \quad(I C L)
\end{gathered}
$$$$
\text { We define } \quad U\left(\theta_{H}, w_{H}, q_{H}\right)=U_{H} \quad \text { and }
$$
$U\left(\theta_{L}, w_{L}, q_{L}\right)=U_{L}$, then these constraints can be rewritten as:

$$
\begin{aligned}
& U_{H} \geq 0 \quad(I R H) \\
& U_{L} \geq 0 \quad(I R L) \\
& U_{H} \geq U_{L}-\Delta \theta q_{L} \quad(I C H) \\
& U_{L} \geq U_{H}+\Delta \theta q_{H} \quad(I C L)
\end{aligned}
$$

Note that even we restrict the higher cost type supplier's utility as $U_{H}=0$, the lower cost type supplier can also receive positive utility $\Delta \theta q_{H}$, which represents the lower cost agent's information rent. We have $\left(q_{H}-q_{L}\right)\left(\theta_{H}-\theta_{L}\right) \leq 0$ by adding ICL and ICH. Because $\theta_{H}>\theta_{L}$ the monotonicity constraint $q_{H} \leq q_{L}$ is satisfied. Furthermore, because $q_{L}>0$ and $\theta_{H}>\theta_{L}$, it's easy to find that $\mathrm{ICH}$ is a loose constraint. 
The firm's optimization problem is (2) subject to (3). We solve it using the standard technique by restricting the higher cost type to receive zero utility, relaxing $\mathrm{ICH}$ (loose constraint). The firm's optimization problem becomes:

$$
\begin{aligned}
& V=p\left[S\left(q_{H}\right)-w_{H}\right]+(1-p)\left[S\left(q_{L}\right)-w_{L}\right] \\
& \text { s.t. } \\
& w_{H}-\theta_{H} q_{H}+\lambda \frac{w_{H}-w_{L}}{\Delta \theta}=0 \\
& w_{L}-\theta_{L} q_{L}+\lambda \frac{w_{L}-w_{H}}{\Delta \theta}=w_{H}-\theta_{L} q_{H}+\lambda \frac{w_{H}-w_{L}}{\Delta \theta}
\end{aligned}
$$

We solve $w_{H}$ and $w_{L}$ from the constraints and replace them into the optimization problem.

$$
\begin{aligned}
& w_{H}=\theta_{H} q_{H}+\frac{\theta_{L} \lambda}{2 \lambda+\Delta \theta}\left(q_{L}-q_{H}\right) \\
& w_{L}=\theta_{H} q_{H}+\frac{\theta_{L}(\lambda+\Delta \theta)}{2 \lambda+\Delta \theta}\left(q_{L}-q_{H}\right)
\end{aligned}
$$

Because $\Delta \theta=\theta_{H}-\theta_{L}>0$ and $q_{L}>q_{H}$, we have $w_{L}>w_{H}$.

We use formula (6) to replace $w_{H}$ and $w_{L}$ in (5), the firm's optimization problem becomes:

$$
\begin{aligned}
& \max _{q_{H}, q_{L}} p\left\{S\left(q_{H}\right)-\left[\theta_{H} q_{H}+\frac{\theta_{L} \lambda}{2 \lambda+\Delta \theta}\left(q_{L}-q_{H}\right)\right]\right\} \\
& +(1-p)\left\{S\left(q_{L}\right)-\left[\theta_{H} q_{H}+\frac{\theta_{L}(\lambda+\Delta \theta)}{2 \lambda+\Delta \theta}\left(q_{L}-q_{H}\right)\right]\right\}
\end{aligned}
$$

We solve the above optimization and the optimal output satisfies:

$$
\begin{aligned}
S^{\prime}\left(q_{L}^{*}\right) & =\frac{\theta_{L}}{1-p}\left[\frac{\lambda+(1-p) \Delta \theta}{2 \lambda+\Delta \theta}\right] \\
S^{\prime}\left(q_{H}^{*}\right) & =\frac{\theta_{H}}{p}-\frac{\theta_{L}}{p} \frac{\lambda+(1-p) \Delta \theta}{2 \lambda+\Delta \theta}
\end{aligned}
$$

\section{Comparative statics}

When we set $\lambda=0$, the optimal solution becomes $S^{\prime}\left(q_{H}^{*}\right)=\theta_{H}+\frac{1-p}{p} \Delta \theta$, and $S^{\prime}\left(q_{L}^{*}\right)=\theta_{L}$. There's no output distortion for the efficient supplier, but the higher cost supplier has a downward output distortion. When there's no social comparison, the ability difference only restricts the higher cost type supplier's output, and the higher $\Delta \theta$ leads to lower $q_{H}$, that is, the bigger gap between two output levels (because $q_{L}$ is fixed). Furthermore, if only one type supplier exists in the market ( $p=0$ or $p=1$, the complete information situation), the optimal output becomes $S^{\prime}\left(q_{L}^{\#}\right)=\theta_{L}$ or $S^{\prime}\left(q_{H}^{\#}\right)=\theta_{H}$. The solution degenerates into a standard complete information form.

When there exists social comparison, or $\lambda>0$, the output under incomplete information has the following properties:

Proposition 1: With social comparison, the higher ability difference $\Delta \theta$ leads to lower output difference $\Delta q=q_{L}-q_{H}$.
Proof: we set $S^{\prime}(q)=x$, because $S^{\prime \prime}(q)<0$, the higher $x$ means the lower $q$. For $S^{\prime}\left(q_{L}^{*}\right)=x$, we have $\frac{\partial x}{\partial \Delta \theta}>0$. For the higher $\Delta \theta$, we have higher $x$ and lower $q_{L}^{*}$. For $S^{\prime}\left(q_{H}^{*}\right)=y$, we have $\frac{\partial y}{\partial \Delta \theta}<0$. For the (5) higher $\Delta \theta$, we have lower $y$ and higher $q_{H}^{*}$. We combine the above two conditions, the proposition is proofed.

Proposition 1 means that if the suppliers care about the transfer difference associated with ability difference, the higher cost supplier would reverse his output to a higher level, and the lower cost type supplier would lower his output downward. (For example, the L type supplier receives additional positive utility, she can reduce her (6)effort cost (by reducing quantity $q_{L}$ ); for the $H$ type agent, she receives disutility from social comparison, so she has to increase her output $q_{H}$.)

Proposition 2: The lower probability $p$ leads to higher output difference $\Delta q$, and the higher probability $p$ leads to lower output difference $\Delta q$.

Proof: The supplier's output level is correlated with probability $p$. From equation (8), we have $\partial S^{\prime}\left(q_{H}^{*}\right) / \partial p<0$ and $\partial S^{\prime}\left(q_{L}^{*}\right) / \partial p>0$. That is, with a lower probability $p$, we have lower $q_{H}^{*}$ and higher $q_{L}^{*}$, the output difference $\Delta q$ would be higher; similarly, a higher probability $p$ leads to higher $q_{H}^{*}$ and lower $q_{L}^{*}$, then we have a lower output difference $\Delta q$.

For a better understanding of the proposition 2 above, let's look at an extreme case. A lower probability $p$ (e.g. $p=0$ ) means that only the lower cost supplier exists on the market, we have $q_{H}=0$ and $q_{L}>0$; similarly, if the probability $p$ is very high (e.g., $p=1$ ), we have $q_{H}>0$ and $q_{L}=0$. Remember that $q_{L}^{*}>q_{H}^{*}$ if $0<p<1$, we can conclude that probability has effects on output differences in such way.

Proposition 3: (a) If $p<1 / 2, q_{L}^{*}>q_{L}^{\#}$ and $q_{H}^{*}<q_{H}^{\#}$, social comparison increases (decreases) the lower (higher) cost agent's output, the output difference will increase; (b) If $p>1 / 2, q_{L}^{*}<q_{L}^{\#}$ and $q_{H}^{*}>q_{H}^{\#}$, social comparison decreases (increases) the lower(higher) cost agent' output, and narrow the output difference. (c) If $p=1 / 2$, the output level is the same as there has no social comparison, and the higher $\Delta \theta$ leads to higher output difference $\Delta q$.

$$
\text { Proof: Note that } S^{\prime}\left(q_{L}^{\#}\right)=\theta_{L}
$$
and $\quad S^{\prime}\left(q_{H}^{\#}\right)=\theta_{H} \quad$.If $\quad p=1 / 2 \quad$, we have $S^{\prime}\left(q_{H}^{*}\right)=\theta_{H}+\Delta \theta$ and $S^{\prime}\left(q_{L}^{*}\right)=\theta_{L}$, it has the same output level comparing with the $\lambda=0$ case, or the selfregarding situation. That is, if the firm has the belief that two different cost type suppliers have equal probability, then the social comparison has no effect on output. Furthermore, because $\quad \partial S^{\prime}\left(q_{H}^{*}\right) / \partial p<0$ 
and $\partial S^{\prime}\left(q_{L}^{*}\right) / \partial p>0$, combing with proposition 2 , the proposition is proofed.

Compare with the complete information condition, asymmetric information with social comparison distorts the socially optimal output level. The different thing here is that the distortion exists for both supplier types, and the output here can be higher than the social optimal (e.g., $p<1 / 2, q_{L}^{*}>q_{L}^{\#}$ and $p>1 / 2, q_{H}^{*}>q_{H}^{\#}$ ), the upward distortion can be found when there exists social comparison.

Proposition 4: (a) If $p<1 / 2$, the higher $\lambda$ leads to higher output difference $\Delta q$; (b) If $p>1 / 2$, the higher $\lambda$ leads to lower output difference $\Delta q$; (c) If $p=1 / 2, \lambda$ has no effect on output difference.

Proof: Note that if $p=1 / 2, S^{\prime}\left(q_{H}^{*}\right)=\theta_{H}+\Delta \theta$ and $S^{\prime}\left(q_{L}^{*}\right)=\theta_{L}$. The social comparison parameter $\lambda$ does not affect the output. we derivate the output with respect to $\lambda$, we have the following equations and the proposition 4 is proofed.

$$
\begin{aligned}
& \left\{\begin{array}{l}
\partial S^{\prime}\left(q_{H}^{*}\right) / \partial \lambda>0, \text { if } p<1 / 2 \\
\partial S^{\prime}\left(q_{H}^{*}\right) / \partial \lambda<0, \text { if } p>1 / 2
\end{array}\right. \\
& \left\{\begin{array}{l}
\partial S^{\prime}\left(q_{L}^{*}\right) / \partial \lambda<0, \text { if } p<1 / 2 \\
\partial S^{\prime}\left(q_{L}^{*}\right) / \partial \lambda>0, \text { if } p>1 / 2
\end{array}\right.
\end{aligned}
$$

The social comparison parameter represents the strength of the supplier's fairness perception adjusted by their ability difference. Proposition 3 has stated that probability distribution has a clear impact on the supplier's output level and difference, and lower $p$ leads to higher output difference. If the suppliers care their transfer difference more, the effect can also be amplified or diminished in the same direction.

Proposition 5: The social comparison will not change the suppliers' utility.

The supplier's constraints in equation (3) can be rewritten as equation (4). Both ICL and IRH constraints are tight means that the higher cost supplier receives zero utility, and the lower cost supplier receives information rent $\Delta \theta q_{H}$ and Proposition 5 is proofed. The proposition means that social comparison has no effects on the supplier's welfare. The conclusion of the classical model is still valid here: only the efficient agent receives positive information rent.

\section{ConClusion}

Social comparison and fairness concern are pervasive in a large number of areas such as consumer's behavior and labor relationship. Previous studies have shown that fairness concern or social comparison would affect the agent's performance but ignoring their ability difference. This paper presents a general framework to analyze social comparison adjusted by their ability level.

In this paper, we consider a screening model where the firm needs an external supplier to offer him products or services. We use their ability difference to adjust their social comparison perception and analyze how social comparison affects the optimal contract variables. Our analysis shows that social comparison would amplify the output difference between the two different cost type suppliers. If there is a higher probability that the higher efficiency supplier on the market, then the output difference between the two types providers will also be higher. When the suppliers care more about social comparison, this effect would also be amplified or diminished.

\section{ACKNOWLEDGMENT}

This paper is supported by the Natural Sciences Foundation of China under the Grant No.71972026.

\section{REFERENCES}

1. I. McCarthy and A. Anagnostou, "The impact of outsourcing on the transaction costs and boundaries of manufacturing," International Journal of Production Economics, vol. 88, no. 1, pp. 61-71, 2004.

2. M. Antelo and L. Bru, "Outsourcing or restructuring: The dynamic choice," International Journal of Production Economics, vol. 123, no. 1, pp. 1-7, 2010.

3. O. Bustinza, D. Arias-Aranda, and L. GutierrezGutierrez, "Outsourcing, competitive capabilities and performance: an empirical study in service firms," International Journal of Production Economics, vol. 126, no. 2, pp. 276-288, 2010.

4. F. Nordin, "Linkages between service sourcing decisions and competitive advantage: A review, propositions, and illustrating cases," International Journal of Production Economics, vol. 114, no. 1, pp. 40-55, 2008.

5. J. I. Moline and A. M. Coves, "Supplier evaluation and selection: A' review of the literature since 2007," in Managing Complexity. Springer, 2014, pp. 217-223.

6. G. A. Akerlof, "The market for" lemons": Quality uncertainty and the market mechanism," Quarterly Journal of Economics, vol. 84, 1970.

7. J.-J. Laffont and D. Martimort, The theory of incentives: the principalagent model. Princeton university press, 2009.

8. P. Bolton, M. Dewatripont et al., Contract theory. MIT press, 2005.

9. G. E. Bolton and A. Ockenfels, "Erc: A theory of equity, reciprocity, and competition," American Economic Review, vol. 90, no. 1, pp. 166-193, 2000.

10. G. Charness and M. Rabin, "Understanding social preferences with simple tests," The Quarterly Journal of Economics, vol. 117, no. 3, pp. 817-869, 2002.

11. E. Fehr and K. M. Schmidt, "A theory of fairness, competition, and cooperation," The Quarterly Journal of Economics, vol. 114, no. 3, pp. 817-868, 1999. 
12. S. H. Slichter, "Industrial morale," The Quarterly Journal of Economics, vol. 35, no. 1, pp. 36-60, 1920.

13. G. A. Akerlof, "Labor contracts as partial gift exchange," The Quarterly Journal of Economics, vol. 97, no. 4, pp. 543-569, 1982.

14. A. Cohn, E. Fehr, B. Herrmann, and F. Schneider, "Social comparison and effort provision: Evidence from a field experiment," Journal of the European Economic Association, vol. 12, no. 4, pp. 877-898, 2014.

15. E. Katok and V. Pavlov, "Fairness in supply chain contracts: A laboratory study," Journal of Operations Management, vol. 31, no. 3, pp. 129-137, 2013.

16. V. Pavlov and E. Katok, "Fairness and coordination failures in supply chain contracts," Available at SSRN 2623821, 2011.

17. F. Englmaier and S. Leider, "Contractual and organizational structure with reciprocal agents," American Economic Journal: Microeconomics, vol. 4, no. 2, pp. 146-83, 2012.

18. _ - "Managerial payoff and gift-exchange in the field," Review of Industrial Organization, Nov 2019. [Online]. Available: https://doi.org/10.1007/s11151019-09737-y

19. G. D. Jenkins, Skill-based pay: practices, payoffs, pitfalls and prescriptions a study. American Compensation Association, 1992.

20. N. Gupta, G. D. Jenkins Jr, and W. P. Curington, "Paying for knowledge: Myths and realities," National Productivity Review, vol. 5, no. 2, pp. 107123, 1986.

21. J. D. Shaw, N. Gupta, A. Mitra, and G. E. Ledford Jr, "Success and survival of skill-based pay plans," Journal of Management, vol. 31, no. 1, pp. 28-49, 2005.

22. C. H. Fay, The Executive Handbook on Compensation: Linking Strategic Rewards to Business Performance. Simon and Schuster, 2001. 